(C) Cambridge University Press 2019. This is an Open Access article, distributed under the terms of the Creative Commons Attribution licence (http://creativecommons.org/licenses/by/4.0/), which permits unrestricted re-use, distribution, and reproduction in any medium, provided the original work is properly cited.

\title{
Pest kill rate as aggregate evaluation criterion to rank biological control agents: a case study with Neotropical predators of Tuta absoluta on tomato
}

\author{
J.C. van Lenteren ${ }^{1 *} \odot$, V.H.P. Bueno ${ }^{2}$, G. Burgio ${ }^{3}$, A. Lanzoni ${ }^{3}$, \\ F.C. Montes ${ }^{2}$, D.B. Silva ${ }^{4}$, P.W. de Jong ${ }^{1}$ and L. Hemerik ${ }^{5}$ \\ ${ }^{1}$ Laboratory of Entomology, Wageningen University, P.O.Box 16, 6700AA, \\ Wageningen, The Netherlands: ${ }^{2}$ Department of Entomology, Laboratory of \\ Biological Control, Federal University of Lavras, P. O. Box 3037, 37200-000 \\ Lavras, MG, Brazil: ${ }^{3}$ Department of Agricultural and Food Sciences, \\ University of Bologna, Viale Fanin, 42, 40127 Bologna Italy: ${ }^{4}$ Department of \\ Entomology and Acarology, Luiz de Queiroz College of Agriculture (USP/ \\ ESALQ), Piracicaba, Brazil: ${ }^{5}$ Biometris, Department of Mathematical and \\ Statistical Methods, Wageningen University, P.O. Box 16, Wageningen 6700 \\ AA, The Netherlands
}

\begin{abstract}
Tuta absoluta (Meyrick), a key pest of tomato, is quickly spreading over the world and biological control is considered as one of the control options. Worldwide more than 160 species of natural enemies are associated with this pest, and an important challenge is to quickly find an effective biocontrol agent from this pool of candidate species. Evaluation criteria for control agents are presented, with the advantages they offer for separating potentially useful natural enemies from less promising ones. Next, an aggregate parameter for ranking agents is proposed: the pest kill rate $k_{\mathrm{m}}$. We explain why the predator's intrinsic rate of increase cannot be used for comparing the control potential of predators or parasitoids, while $k_{\mathrm{m}}$ can be used to compare both types of natural enemies. As an example, kill rates for males, females and both sexes combined of three Neotropical mirid species (Campyloneuropsis infumatus (Carvalho), Engytatus varians (Distant) and Macrolophus basicornis (Stål)) were determined, taking all life-history data (developmental times, survival rates, total nymphal and adult predation, sex ratios and adult lifespan) into account. Based on the value for the intrinsic rate of increase $\left(r_{\mathrm{m}}\right)$ for T. absoluta and for the kill rate $k_{\mathrm{m}}$ of the predators, we predict that all three predators are potentially able to control the pest, because their $k_{\mathrm{m}}$ values are all higher than the $r_{\mathrm{m}}$ of the pest. Using only $k_{\mathrm{m}}$ values, we conclude that E. varians is the best candidate for control of T. absoluta on tomato, with C. infumatus ranking second and M. basicornis last.
\end{abstract}

Keywords: Campyloneuropsis infumatus, Engytatus varians, Macrolophus basicornis, biological control, Miridae, South American tomato moth, natural enemy efficacy, natural enemy evaluation criteria

(Accepted 27 February 2019; First published online 10 April 2019)

\footnotetext{
${ }^{*}$ Author for correspondence

Phone: +31 317482327

Fax: +31 317484821

E-mail: Joop.vanLenteren@wur.nl
} 


\section{Introduction}

The question whether evaluation criteria can be used - and if so, which ones - to rank the biological control potential of natural enemies has long been discussed, but remains far from being solved (e.g. van Lenteren, 1980, 2010; Stiling \& Cornelissen, 2005; McEvoy, 2018). That this issue is still very relevant today can be illustrated with the case of the South American tomato moth Tuta absoluta (Meyrick) (Lepidoptera: Gelechiidae), which was accidentally introduced from Latin America into Spain in 2006. In just 12 years, the moth has spread over mainland Europe, the Mediterranean region, the African continent and a substantial part of Asia, and now occurs in more than 80 countries. Based on climate modelling, it is expected that dispersal of T. absoluta will continue and that invasions in, for example, China and North America are likely to happen in the near future (Biondi et al., 2018). Due to its leaf mining habit, the pest is difficult to control with synthetic pesticides, demanding frequent applications, resulting in fast development of pesticide resistance, and negative side effects on biodiversity, the environment and health of farmers and consumers. Biocontrol might offer an alternative, but which natural enemy to use? More than 160 species of predators and parasitoids, as well as a number of pathogens have been listed in association with T. absoluta (Biondi et al., 2018; Ferracini et al., 2019). This large number is promising, but creates also a serious problem: how to select an effective and safe biocontrol agent from this large list of species?

Many suggestions about biocontrol agent selection have been published, ranging from quick fits like the collection and release of any natural enemy that might attack the pest (the 'hit or miss approach'; DeBach, 1964), to rather timeconsuming research programmes which include behavioural and ecological studies, as well as environmental risk assessments (van Lenteren, 1980; van Lenteren \& Woets, 1988; van Driesche \& Bellows 1996; Stiling \& Cornelissen, 2005; van Lenteren et al., 2006; Heimpel \& Mills, 2017; McEvoy, 2018). Often it takes about 10 years to find, evaluate, select and eventually market a natural enemy, which is similar to the time needed to find a new synthetic pesticide. Research in biocontrol is usually financed by public funding, and often dependent on short term aid. Thus, simple evaluation procedures for selection of natural enemies prior to field releases would be much appreciated, but developing simple procedures is not an easy task. Still, there are a number of issues related to biocontrol agent quality that can be used in an evaluation process and these are listed in table 1 . Most issues (1-10) concern biological characteristics of the candidate species; others are based on experience in other biocontrol projects (11), concern economics of biocontrol (12-14) or relate to problems of obtaining specimens of exotic natural enemies (15). The issues are not listed in order of priority for evaluation and depend on the type of biocontrol programme. Evaluation of natural enemies to be used in augmentative biocontrol starts with issues 5 (not causing side effects), 12, 14 and 15 (costs of mass rearing, market potential, complexity of regulations). In a classical biocontrol project, one will start with issue 15 , next 11 (similar species effective in similar crop elsewhere), then followed by issues 1-9, while little attention is paid to issues 10 (ability to survive on alternative food), 12 and 14 .

Generally, literature information about the potential biocontrol agent, or a related species, and some simple experiments will suffice to form an opinion about issues $1-5$. Work on issues $6-10$ is more time consuming. Particularly rather
Table 1. Issues related to pre-introduction evaluation of natural enemies.

Issues related to biology of natural enemy

1. Seasonal synchronisation with pest (for parasitoids and predators)

2. Developmental synchronisation with pest (mainly for parasitoids)

3. Climatic adaptation to area where used

4. Capability to search for pest on target crop and establish a population

5. Few or no negative side effects on crop, environment and other organisms

6. Preference for pest species

7. High pest kill ability

8. Good pest finding capacity

9. Effective responsiveness to changes in pest density

10. Ability to survive on alternative food in the absence of pest

Issues related to experience with natural enemy in other biocontrol project

11. Same or similar species effective in same or similar crop and climate elsewhere

Issues related to production, marketing and registration of natural enemy

12. Cost-effective mass production, shipment and release

13. Robust and reliable performance under practical production conditions

14. Market potential

15. Complexity of importation and/or registration procedures

complicated environmental risk assessments are nowadays crucial elements of the evaluation process, as many governments demand information about possible risks caused by the introduction of exotic species (Bale, 2011). Issues 12 and 14 , mass-production costs and market potential, are only relevant for augmentative biocontrol, which often is a commercial activity. Issue 15, registration procedures and complexity of Access and Benefit Sharing procedures of the Nagoya Protocol related to use of exotic genetic resources are new problems for biocontrol. The Nagoya Protocol came into force in October 2014 and has brought about an almost complete stop to foreign natural enemy exploration programmes (Cock et al., 2016).

The main aim of using the list of evaluation issues is not per sé to find the best natural enemy, but primarily to quickly exclude those natural enemies that might (1) not be effective at all, (2) cause unacceptable negative effects, (3) are too expensive to mass produce or have little market potential and (4) will have to undergo unworkable Access and Benefit Sharing procedures. It is not an exception to find tens or even more than hundred species of natural enemies attacking a pest. Use of the evaluation criteria mentioned in table 1 helps to reduce this large number of candidates to only a few, and results in spending the limited amount of research money on those species that might eventually be applied for control of the target pest.

Earlier work by our group has shown that by using data about issues 1-6 and 8, two species of natural enemies we found in the field and that attack T. absoluta in the laboratory on tobacco plants, could be removed from the list of candidates for T. absoluta control on tomato: Geocoris punctipes (Say) (Hemiptera: Geocoridae) and Orius insidiosus (Say) (Hemiptera: Anthocoridae) (see discussion and Bueno et al., 2013). On the other hand, evaluation of three Neotropical mirids (Campyloneuropsis infumatus (Carvalho), Engytatus varians 
(Distant) and Macrolophus basicornis (Stål) (Hemiptera: Miridae)) showed that they are seasonally and developmentally synchronized with the pest, are well able to function at the climatic conditions under which tomatoes are produced (Bueno et al., 2018a, b), are capable to establish a population on tomato, are not caught in the glandular tomato trichomes (Bueno et al., 2013), kill T. absoluta eggs and larvae (van Lenteren et al., 2016, 2017, 2018a), and cause little injury to tomato plants and fruit as a result of phytophagy (Silva et al., 2017). Specific information concerning issues 8 and 9 have not yet been collected for the three Neotropical mirids, though we know that they react to and are attracted by volatiles produced by tomato plants after attack by the pest (Silva et al., 2018). Cheap mass production methods (issue 12) for mirids have already been developed by commercial natural enemy producers but these methods are, understandably, not publicly available. However, laboratory populations can easily be reared on the factitious host Ephestia kuehniella (Zeller) (Lepidoptera: Pyralidae) (Bueno et al., 2018a, b). If, in the near future, experiments on a commercial production greenhouse scale show effective control of tomato pests by one or more of these mirids, they certainly have a large market potential, particularly due to the fact that they seem to cause much less injury to plants and fruit (Silva et al., 2017), than the Paleotropical mirids currently used in Europe (Castañé et al., 2011). However, an important future problem for use of these mirids might be to obtain permission to export them to other areas (issue 15).

In this paper, we will consider the importance of issue 7 , the capacity of the natural enemy to kill sufficient pest individuals per unit of time. The best available single description of the population growth potential of a species under given conditions is still the intrinsic rate of natural increase $\left(r_{\mathrm{m}}\right)$ (Southwood, 1966). For solitary parasitoids, this parameter can also be used to compare their capacity to kill hosts, because in solitary parasitoids each egg laid means that a host is killed (van Lenteren, 2010). The parameter $r_{\mathrm{m}}$ has recently been used for comparison of several predators of $T$. absoluta as well (e.g. Mollá et al., 2014). But the intrinsic rate of natural increase only provides information how quickly a predator population can grow, and does not provide an estimate on how many prey items it can kill. Earlier, Janssen \& Sabelis (1992) tried to find a way to compare the intrinsic rate of natural increase and predation capacity of phytoseiid predatory mites. They concluded that the predation rate would be an important characteristic for obtaining an estimate of their biocontrol capability. However, they did not investigate the matter any further. Actually, for parasitoids the $r_{\mathrm{m}}$ also has its limitations to estimate the host kill rate, as parasitoids may kill hosts by non-reproductive effects like host feeding and stinging hosts with their ovipositor (Abram et al., 2019). Therefore a new parameter was proposed by Tommasini et al. (2004) and van Lenteren (2010) to be able to compare the pest kill capacity of predators and parasitoids: the pest kill rate $\left(k_{\mathrm{m}}\right)$. To determine the pest kill rate for parasitoids, the number of hosts killed by non-reproductive effects is added to the number of eggs laid by the parasitoid. We will compare kill rates of predators and parasitoids of T. absoluta in a future paper.

For predators, $k_{\mathrm{m}}$ is the age-specific predation capability per unit of time, based on the development and survival of eggs and nymphs, the sex ratio and total predation by all immature stages and the adults. For a predator to be efficient in classical biocontrol, its pest kill rate $\left(k_{\mathrm{m}}\right)$ theoretically needs to be of the same magnitude as, or higher than the population growth rate $\left(r_{\mathrm{m}}\right)$ of the pest (Tommasini et al., 2004). However, in augmentative biocontrol, this is not a strict prerequisite as a pest kill rate lower than the population growth rate of the pest can be compensated by regular releases of large numbers of predators. Still, a high kill rate is appreciated as it will reduce the costs of the biocontrol programme, because fewer releases or fewer natural enemies per release are needed. Tommasini et al. (2004) used the pest kill rate parameter to compare the predation capacity of four Orius species preying on adult thrips (Frankliniella occidentalis (Pergande) (Thysanoptera: Thripidae)), and found that O. laevigatus (Fieber) showed the highest pest kill rate. Although O. laevigatus has been used since the mid-1990s, it is since Tommasini's research the most used species for biocontrol of thrips pests in Europe, and replaced use of the exotic O. insidiosus (van Lenteren et al., 2018b). After the Tommasini et al. (2004) publication, the pest kill rate has, to our knowledge, not been used in predator comparisons, which might be explained by the large amount of work needed to collect lifetime predation data. Recently, we have measured the lifetime predation of the three species of Neotropical mirids that prey on T. absoluta (van Lenteren et al., 2017, 2018a). These data allow us to calculate the aggregate parameter pest kill rate for comparison of the predation capacity of these mirids.

In this paper, we first present summarized life-table data of the pest T. absoluta and the three mirid species. Next, population growth rates of the pest and the mirids, as well as the pest kill rates of the mirids are calculated. Finally, we will hypothesize about the pest reduction capacity of these predators and the value of the pest kill rate parameter.

\section{Material and methods}

\section{Data collection for life tables and lifetime predation capacities of three mirid species}

Collection and rearing of T. absoluta and the three species of mirid predators is described in van Lenteren et al. (2018a). Details about the life-table experiments and results for T. absoluta can be found in Silva et al. (2015). Data about developmental time and egg survival of the three mirids have been published by Bueno et al. (2018b). The experimental procedures and the results of T. absoluta egg predation by all nymphal stages of the three mirids can be found in van Lenteren et al. (2017) and for predation by the adults in van Lenteren et al. (2018a); the same two papers also provide data on development and survival of nymphs and adults, sex ratio and adult lifespan. Experiments with T. absoluta were performed in climate rooms at $25 \pm 2{ }^{\circ} \mathrm{C}, 70 \pm 10 \% \mathrm{RH}$ and $12 \mathrm{~h}$ photophase, and with the three mirid predators at $24 \pm 1^{\circ} \mathrm{C}$, with the same RH and photophase.

\section{Data analysis}

Intrinsic rate of natural increase $\mathbf{r}_{m}$ and the intrinsic pest kill rate $\mathbf{k}_{m}$ according to Birch approach

Life-table parameters of T. absoluta were studied following the methodology explained by Birch (1948). $x=$ pivotal age in days (including immature stages), $l_{x}=$ age-specific survival (including immature mortality), $m_{x}=$ age-specific fertility (the number of females produced per female alive at age $x$ ) were determined in order to calculate the gross reproductive rate GRR $\left(\mathrm{GRR}=\sum_{x} m_{x}\right)$, the net reproductive rate $R_{0}\left(R_{0}=\sum_{x} l_{x} m_{x}\right)$, and the intrinsic rate of natural increase $r_{\mathrm{m}}$ 
$\left(r_{\mathrm{m}}=\ln R_{0} / T\right)$, where $T$ is the generation time $\left(T=\sum_{x} l_{x} m_{x} x\right)$ $\left.R_{0}\right)$, and the finite rate of increase $\lambda\left(\lambda=\mathrm{e}^{r_{\mathrm{m}}}\right)$.

The pest kill rate $\left(k_{\mathrm{m}}\right)$ of the three mirid species when fed with T. absoluta eggs ad libitum was calculated using the same formula of $r_{\mathrm{m}}$, but the age-specific fertility $\left(m_{x}\right)$ was substituted with the age-specific predation $\left(k_{x}\right)$ both during the nymphal and the adult stages. Thus $k_{\mathrm{m}}=\ln K_{0} / T_{\mathrm{k}}$, where: $T_{\mathrm{k}}$ (predation time) is the mean period during a generation where the predator actually prey and is estimated by calculating the mean predator ages for each age $x$ weighted by the net number of prey consumed at that age $\left(T_{\mathrm{k}}=\sum_{x} l_{x} k_{x} x / \sum_{x} l_{x} k_{x}\right) \cdot T_{\mathrm{k}}$ can be considered as the time required for a population to predate at a rate of $K_{0} . K_{0}$ is the net consumption rate $\left(K_{0}=\sum_{x} l_{x} k_{x}\right)$, i.e. the number of preys killed during a generation of the predator, corrected by natural mortality.

Intrinsic rate of natural increase $\mathrm{r}_{m}$ and the intrinsic pest kill rate $\mathrm{k}_{m}$ according to Lotka-Euler approach

As we did collect daily fertility data of cohorts for T. abso$l u t a$, as well as daily predation data for the three mirid species, we could use a more accurate method to calculate the intrinsic rates of increase and pest kill rate values with the Euler-Lotka equation (Lotka, 1907; Lotka \& Sharpe, 1911): $\Sigma\left[\mathrm{e}^{-\left(r_{\mathrm{m}} x\right)} l_{x} m_{x}\right]=1$ and $\Sigma\left[\mathrm{e}^{-\left(k_{\mathrm{m}} x\right)} l_{x} k_{x}\right]=1$. The values for $r_{\mathrm{m}}$ and $k_{\mathrm{m}}$ are obtained by iteration, i.e. by updating $r_{\mathrm{m}}$ and $k_{\mathrm{m}}$ values until the formula gives the required value of 1 . The Jackknife re-sampling technique was used to calculate the mean and standard error associated with population parameters for T. absoluta (Maia et al., 2000).

\section{Results \\ Intrinsic rate of natural increase $\mathrm{r}_{m}$ of $\mathrm{T}$. absoluta}

Data on development and survival of eggs, larvae and pupae, and life span, egg production and sex ratio of adults of T. absoluta are summarized in table 2. Detailed tables with adult life-history data used for calculation of the intrinsic rate of natural increase of T. absoluta can be found in the Supplementary Electronic Material.

The intrinsic rates of natural increase $r_{\mathrm{m}}$ of T. absoluta estimated with the Birch approach and the Lotka-Euler approach are similar and this also holds for the other life-table parameters (table 3).

\section{Pest kill rate $\mathrm{k}_{m}$ of the three mirid predators}

Data collected during a series of experiments (see publications mentioned in Section 'Data collection for life tables and lifetime predation capacities of three mirid species', also for the statistical tests we used) are summarized in table 4 . Development times and percentages survival of eggs were similar for the mirid species. Development times of mirid nymphs did not differ significantly between the sexes, and were similar across species. Total nymphal development time was significantly longer for $M$. basicornis (table 4) than for the other two species. Nymphal survival was about $93 \%$ for all three species. As nymphal mortality could not be attributed to sex, it is not included in the calculation of the kill rate of the separate sexes in table 5, and will have resulted in a slight overestimate of the kill rate. We can illustrate the magnitude of overestimation by calculation of kill rates for both sexes combined
Table 2. Development of eggs, larvae and pupae (days \pm SE), survival of eggs, larvae and pupae $(\% \pm \mathrm{SE})$, sex ratio, longevity of males and females (days \pm SE) and average number of eggs laid per female $\left( \pm\right.$ SE) of Tuta absoluta at $25 \pm 2{ }^{\circ} \mathrm{C}, \mathrm{RH} 70 \pm 10 \%$ and $12 \mathrm{~h}$ photophase.

\begin{tabular}{lcl}
\hline Egg development (days \pm SE) & $3.6 \pm 0.08$ & $N=100$ \\
\% Egg survival & 98.0 & $N=100$ \\
Larval development (days \pm SE) & $8.9 \pm 0.09$ & $N=130$ \\
\% Larval survival & 98.0 & $N=100$ \\
Pupal development males (days \pm SE) & $7.1 \pm 0.26$ & $N=10$ \\
Pupal development females (days \pm SE) & $6.6 \pm 0.20$ & $N=10$ \\
\% Pupal survival & 100 & $N=50$ \\
Sex ratio (female:male) & $0.4: 0.6$ & $N=50$ \\
Longevity females (days \pm SE) & $15.5 \pm 0.60$ & $N=15$ \\
Longevity males (days \pm SE) & $16.5 \pm 0.77$ & $N=15$ \\
Total eggs/female (number \pm SE) & $172.7 \pm 17.29$ & $N=15$ \\
\hline
\end{tabular}

with nymphal mortality included: they are a bit lower than the rates without nymphal mortality included (table 5).

Predation rates by each nymphal stage for male and female nymphs within a species were similar in most cases. The total number of eggs eaten during the nymphal stages was significantly higher for E. varians than for the other two mirids. Detailed tables with nymphal life-history data used for calculation of the pest kill rate can be found in the Supplementary Electronic Material.

Sex ratios of E. varians and M. basicornis did not significantly deviate from a 1:1 ratio (binomial test, $P>0.1$ ). However, the sex ratio of $C$. infumatus was strongly female biased and differed significantly from a 1:1 ratio (binomial test, $P<0.0001$ ).

The daily and total number of eggs eaten by the two sexes of adults of the three mirid species is shown in table 4 . Males eat significantly fewer T. absoluta eggs per day than females. The number of consumed eggs per day of E. varians is significantly higher than that of C. infumatus and M. basicornis, but does not differ between $C$. infumatus and M. basicornis. For more information about daily egg predation over time and survival curves of adults, as well detailed statistical test results, we refer to van Lenteren et al. (2018a); detailed tables with life-history data used for calculation of the pest kill rate can be found in File 2 of the Supplementary Electronic Material.

The pest kill rate $k_{\mathrm{m}}$ of the three mirid predators estimated with the Birch or Lotka-Euler approach show large differences; $k_{\mathrm{m}}$ values are in all cases much higher when estimated with the more precise Lotka-Euler approach (table 5). As expected from predation data presented in table $2, k_{\mathrm{m}}$ values for males are always lower than values for females.

The changes in daily predation rates over the total development period of males and females of the three species are given in fig. 1. The graphs illustrate a consistent increase in predation starting with the first nymphal instar around day 11, culminating in a predation peak during the 5 th nymphal instar around day 25. During the phase of moulting from 5 th instar to adult, predation rates are zero and then pick up again, but are always lower for males than for females.

\section{Discussion}

A lot of new information about natural enemies associated with T. absoluta has become available since the pest started its worldwide invasive journey in 2006 (e.g. Biondi et al., 2018). Until now the best control results have been obtained by 
Table 3. Life-table parameters (mean $\pm \mathrm{SE}$ ) related to intrinsic rate of natural increase $\left(r_{\mathrm{m}}\right)$ for the pest Tuta absoluta.

\begin{tabular}{lccccr}
\hline$R_{0}$ & $T$ & $r_{\mathrm{m}}=\ln R_{0} / T$ & $r_{\mathrm{m}}$ Lotka-Euler & TD & $\lambda$ \\
\hline $83.07 \pm 8.28$ & $23.80 \pm 0.35$ & $0.1859 \pm 0.0038$ & $0.1908 \pm 0.0039$ & $3.63 \pm 0.07$ & $1.2103 \pm 0.0047$ \\
\hline
\end{tabular}

$R_{0}=$ net reproductive ratio; $T=$ mean generation time; $r_{\mathrm{m}}=$ intrinsic rate of increase; TD doubling time, i.e. the time required for the population to double in number, and $\lambda=$ the finite rate of increase.

Table 4. Development in days $( \pm \mathrm{SE}), \%$ survival $( \pm \mathrm{SE})$, sex ratios, life span $( \pm \mathrm{SE})$ and egg predation $( \pm \mathrm{SE})$ data for the predators Campyloneuropsis infumatus, Engytatus varians and Macrolophus basicornis at $24 \pm 1^{\circ} \mathrm{C}, \mathrm{RH} 70 \pm 10 \%$ and $12 \mathrm{~h}$ photophase.

\begin{tabular}{|c|c|c|c|c|c|c|}
\hline & C. infumatus & $N(C i)$ & E. varians & $N(E v)$ & M. basicornis & $N(M b)$ \\
\hline Egg development & $9.9 \pm 0.42$ & 250 & $10.0 \pm 0.40$ & 138 & $10.7 \pm 0.21$ & 332 \\
\hline$\%$ Egg survival & $95.7 \pm 1.07$ & 250 & $92.3 \pm 1.73$ & 138 & $94.3 \pm 1.02$ & 332 \\
\hline Nymphal development & $16.9 \pm 0.12$ & 44 & $16.6 \pm 0.14$ & 42 & $17.9 \pm 0.09$ & 40 \\
\hline$\%$ Nymphal survival & 93.6 & 44 & 93.3 & 42 & 93.0 & 40 \\
\hline Sex ratio (\#fem:male) & $41: 3$ & 44 & $21: 21$ & 42 & $17: 23$ & 40 \\
\hline Total number of eggs eaten by nymphs & $315.1 \pm 4.42$ & 44 & $392.8 \pm 6.19$ & 42 & $330.7 \pm 5.26$ & 40 \\
\hline Total number of eggs eaten by adult males & $336.9 \pm 41.52$ & 20 & $313.4 \pm 39.93$ & 20 & $339.2 \pm 38.89$ & 20 \\
\hline Total number of eggs eaten by adult females & $844.6 \pm 77.31$ & 20 & $668.2 \pm 72.98$ & 20 & $934.3 \pm 127.40$ & 20 \\
\hline Daily number of eggs eaten by males & $13.3 \pm 0.60$ & 20 & $17.3 \pm 0.72$ & 20 & $11.2 \pm 0.39$ & 20 \\
\hline Daily number of eggs eaten by females & $38.9 \pm 2.25$ & 20 & $49.0 \pm 2.30$ & 20 & $35.4 \pm 1.69$ & 20 \\
\hline Longevity males & $26.6 \pm 2.72$ & 20 & $17.0 \pm 2.01$ & 20 & $29.8 \pm 3.11$ & 20 \\
\hline Longevity females & $23.6 \pm 2.87$ & 20 & $14.0 \pm 1.50$ & 20 & $25.6 \pm 3.23$ & 20 \\
\hline
\end{tabular}

generalist mirid predators (Urbaneja et al., 2012), but application of the most frequently used species, Nesidiocorus tenuis (Reuter) (Hemiptera: Miridae), does regularly result in plant and fruit damage (Castañé et al., 2011), so finding a better natural enemy is a priority. In order to efficiently evaluate the biocontrol potential of the many natural enemies of T. absoluta, ranking of species based on selection criteria and a common aggregate parameter would be helpful. Currently, papers, including some of our own, often conclude that a certain predator might be a good candidate after studying one or a few characteristics. Evaluation of natural enemies is now often done with qualitative criteria (Stiling \& Cornelissen, 2005), which might give some information of the potential value of a natural enemy, but it is difficult to weigh the influence of each criterion for an overall conclusion. Still, assessments for some of the criteria might lead to early exclusion of a natural enemy (e.g. 4, 5, 12, 14, 15 in table 1). For example, O. insidiosus is not capable to search on tomato, because it is caught by the sticky, glandular trichomes within seconds after its release (criterion 4; Bueno et al., 2013). Another example is Macrolophus pygmaeus (Rambur) (Hemiptera: Miridae), which cannot establish a population on tomato when only $T$. absoluta is present as a pest (criterion 4; Mollá et al., 2014).

To obtain estimates for the pest kill rate (criterion 7 ), the functional response of a natural enemy is generally determined. Functional response data for the three Neotropical mirid predators (van Lenteren et al., 2016) made us conclude that M. basicornis might be the best candidate for the control of the South American tomato moth in Brazil, because it has the largest maximum predation capacity and reacts in a density-dependent way to the widest range of T. absoluta prey eggs offered (table 6). However, functional response data tend to overestimate predation capacity, as they are usually measured after a period of starvation and during a $24 \mathrm{~h}$ period only. We can illustrate this with the functional response data obtained at the highest prey density presented in van Lenteren et al. (2016) and the data on adult lifetime predation.
In the functional response experiment, female mirids of 2-7 days old were used, so we calculated the daily predation capacity during this 2-7 day period for females used in the lifetime predation experiment. Although the average numbers of eggs eaten by the three species are slightly higher during the 2-7 day period (column 2) than during the whole adult predation period (column 1), daily predation is considerably lower for E. varians and M. basicornis than during the functional response experiment (column 3). Data in column 1 and 2 of table 7 indicate that not $M$. basicornis, but $E$. varians might be the best predator of T. absoluta, as it preys many more eggs per day than the other two mirids. We conclude that functional response data are of limited value for evaluation and ranking of natural enemies.

Information about all evaluation issues for two Paleotropical and three Neotropical mirid species is summarized in table 7. The table shows that $M$. pygmaeus is the poorest candidate for T. absoluta control. Nesidiocorus tenuis has frequently shown to be able to reduce $T$. absoluta numbers well below economic threshold densities (Pérez-Hedo \& Urbaneja, 2016), but has the negative characteristic of causing serious plant and fruit damage (criterion 5) when animal prey is insufficiently available (Castañé et al., 2011), and is therefore classified to partial fit with evaluation criterion 13 (robust and reliable performance). The three Neotropical mirids score similar for all criteria, and when considering quantitative data for criteria 5 and 7 , seem more promising than the European mirids, also because the Neotropical mirids hardly injure tomato plants and fruit (Silva et al., 2017), and kill more prey per day. Criterion 15 (easy importation/registration procedures when exported) are equally complex for all five species. Evaluation of environmental risk caused by these polyphagous predators will demand time-consuming experiments (Bale, 2011). When the predators are aimed for use in new countries that have signed the Nagoya Protocol, complicated Access and Benefit regulations will need to be followed before export (Mason et al., 2018). Nevertheless, data from 
Table 5. Predation parameters related to the pest kill rate $\left(k_{\mathrm{m}}\right)$ of the predators Campyloneuropsis infumatus, Engytatus varians and Macrolophus basicornis.

\begin{tabular}{|c|c|c|c|c|}
\hline Species/sex & $K_{0}$ & $T_{\mathrm{k}}$ & $\begin{array}{c}k_{\mathrm{m}} \\
\ln K_{0} / T_{\mathrm{k}}\end{array}$ & $\begin{array}{c}k_{\mathrm{m}} \text { Lotka- } \\
\text { Euler }\end{array}$ \\
\hline \multicolumn{5}{|l|}{ C. infumatus } \\
\hline Males & 636.22 & 33.96 & 0.1901 & 0.2810 \\
\hline Females & 1113.88 & 35.37 & 0.1983 & 0.2826 \\
\hline Both sexes & 875.02 & 35.38 & 0.1915 & 0.2817 \\
\hline $\begin{array}{l}\text { Both sexes, with } \\
\text { nymphal mortality } \\
\text { included }\end{array}$ & & & & 0.2793 \\
\hline \multicolumn{5}{|l|}{ E. varians } \\
\hline Males & 664.79 & 30.20 & 0.2152 & 0.2956 \\
\hline Females & 980.15 & 31.43 & 0.2191 & 0.2969 \\
\hline Both sexes & 820.95 & 31.34 & 0.2141 & 0.2956 \\
\hline $\begin{array}{l}\text { Both sexes, with } \\
\text { nymphal mortality } \\
\text { included }\end{array}$ & & & & 0.2935 \\
\hline \multicolumn{5}{|l|}{ M. basicornis } \\
\hline Males & 652.69 & 36.51 & 0.1775 & 0.2714 \\
\hline Females & 1255.62 & 40.25 & 0.1773 & 0.2733 \\
\hline Both sexes & 954.49 & 38.96 & 0.1761 & 0.2723 \\
\hline $\begin{array}{l}\text { Both sexes, with } \\
\text { nymphal mortality } \\
\text { included }\end{array}$ & & & & 0.2695 \\
\hline
\end{tabular}

$K_{0}=$ net consumption rate; $T_{\mathrm{k}}=$ mean predation time; $k_{\mathrm{m}}=$ pest kill rate.

table 7 do not allow us to make a ranking of natural enemy potential, with the exception of M.pygmaeus which is performing poorest for several evaluation criteria and would, thus, take the lowest position in a ranking.

For ranking of mirid predators, also the aggregate parameter intrinsic rate of natural increase $\left(r_{\mathrm{m}}\right)$ has been used (e.g. Mollá et al., 2014; Silva et al., 2016). In table 8, we summarized data for life-table parameters of T. absoluta and mirid predators when developing on tomato with $T$. absoluta as prey. Krechemer \& Foerster (2017) determined the life table of T. $a b$ soluta on six commercial tomato cultivars at $20 \pm 2{ }^{\circ} \mathrm{C}, 70 \pm 10 \%$ $\mathrm{RH}$ and $12 \mathrm{~h}$ photophase, among which the same cultivar we used, cv Santa Clara. The $r_{\mathrm{m}}$ value varied from 0.09 for $\mathrm{cv}$ Santa Clara to 0.11 for $\mathrm{cv}$ Cherry. They found lower $r_{\mathrm{m}}$ values than Silva et al. (2016) and we did, which may for a large part be explained by the lower temperatures at which they executed their experiment. Martins et al. (2016) measured lifetable data for T. absoluta on tomato cv Santa Clara at a range of temperatures and we estimated $r_{\mathrm{m}}$ and $R_{0}$ values from their Figure 5 at $26^{\circ} \mathrm{C}, 70 \pm 5 \% \mathrm{RH}$ and a $12 \mathrm{~h}$ photoperiod (table 8). The $r_{\mathrm{m}}$ values found by Martins et al. (2016) are lower than those published by Silva et al. (2016) and the ones we found (this paper). We did not find other papers with $r_{\mathrm{m}}$ values for T. absoluta on tomato. Data on intrinsic rates of natural increase for mirid predators were published by Silva et al. (2016) for C. infumatus, E. varians and M. basicornis, and by Mollá et al. (2014) for M. pygmaeus and N. tenuis. The $r_{\mathrm{m}}$ values presented in both papers are all considerably lower than those found for T. absoluta by Silva et al. (2016) and us. Mollá et al. (2014) conclude that based on the very low $r_{\mathrm{m}}$ value found for M. pygmaeus (0.005), its role in controlling T. absoluta in the absence of other food sources is possibly limited, and that $N$. tenuis with a much higher $r_{\mathrm{m}}$ value $(0.089)$ has a better potential as biocontrol agent of this pest. Silva et al. (2016)
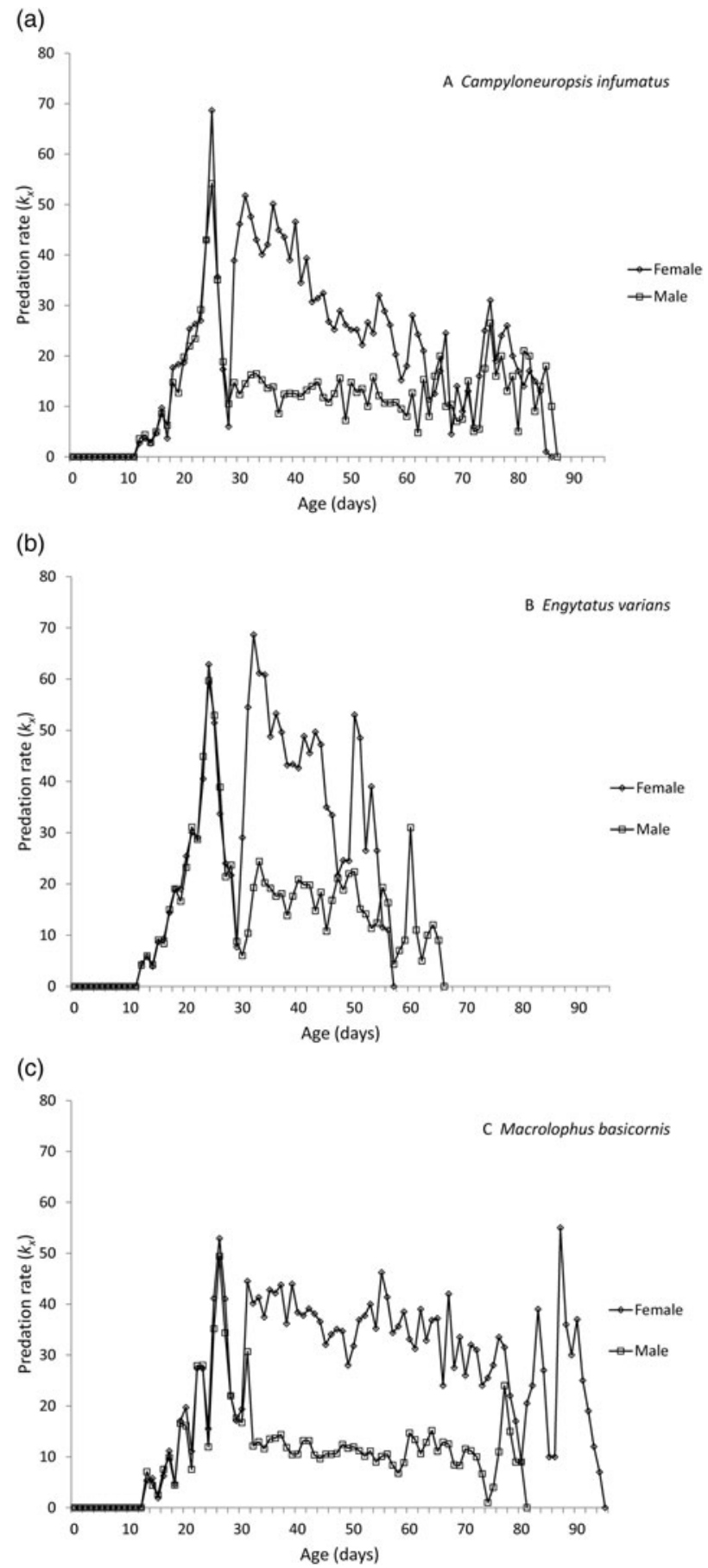

Fig. 1. Daily predation rates for males and females of Campyloneuropsis infumatus (A), Engytatus varians (B) and Macrolophus basicornis (C).

found $r_{\mathrm{m}}$ values of circa 0.11 for the three Neotropical mirids, which are higher than the $r_{\mathrm{m}}$ values for the M. pygmaeus and $N$. tenuis and, thus, they concluded that these Brazilian species might be interesting candidates for control of T. absoluta. Although the conclusions drawn by Mollá et al. (2014) and Silva et al. (2016) might seem logical, the $r_{\mathrm{m}}$ values of predators 
Table 6. Average number of eggs eaten per day (all with \pm SE) of females of Campyloneuropsis infumatus, Engytatus varians and Macrolophus basicornis.

\begin{tabular}{lccr}
\hline Species & $\begin{array}{c}\text { Eggs/day current paper, } \\
\text { whole period }\end{array}$ & $\begin{array}{c}\text { Eggs/day current paper during } \\
\text { test period of func resp exp. }\end{array}$ & Eggs/day func resp exp. \\
\hline C. infumatus & $38.9( \pm 2.25 ; n=472)$ & $45.11( \pm 1.64 ; n=120)$ & $51.0( \pm 4.50 ; n=25)$ \\
E. varians & $49.0( \pm 2.30 ; n=280)$ & $57.01( \pm 2.05 ; n=120)$ & $91.1( \pm 6.07 ; n=25)$ \\
M. basicornis & $35.4( \pm 1.69 ; n=515)$ & $38.75( \pm 1.44 ; n=120)$ & $100.8( \pm 3.25 ; n=25)$ \\
\hline
\end{tabular}

Table 7. Pre-introduction evaluation of the mirids Macrolophus pygmaeus (M. pyg), Nesidiocorus tenuis (N. ten), Campyloneuropsis infumatus (C. inf), Engytatus varians (E. var) and Macrolophus basicornis (M. bas) for control of Tuta absoluta.

\begin{tabular}{|c|c|c|c|c|c|c|}
\hline Criterion $\downarrow$ & Mirid species $\rightarrow$ & M. pyg & N. ten & C. inf & E. var & M. bas \\
\hline 1. Seasonal synchronization & & $+{ }^{1}$ & + & + & + & + \\
\hline 2. Developmental synchronization & & - & - & - & - & - \\
\hline 3. Climatic adaptation & & + & + & + & + & + \\
\hline 5. Few or no negative side effects & & + & - & + & + & + \\
\hline 6. Preference for pest species & & - & + & + & + & + \\
\hline 7. High pest kill ability & & - & + & + & + & + \\
\hline 10. Ability to survive on alternative food & & + & + & + & + & + \\
\hline 11. Same/similar species effective in same/similar crop & & ? & ? & ? & ? & $?$ \\
\hline 12. Cost-effective mass production, shipment and release & & + & + & + & + & + \\
\hline 13. Robust and reliable performance in crop production conditions & & - & \pm & $?$ & $?$ & $?$ \\
\hline 14. Market potential & & - & + & + & + & + \\
\hline 15. Easy importation/registration procedures when exported & & - & - & - & - & - \\
\hline
\end{tabular}

$1_{+}=$fits evaluation criterion, $\pm=$partially fits evaluation criterion, $-=$does not fit evaluation criterion, $?=$ published information is insufficient to draw a conclusion.

Table 8. Literature data for life-table parameters of Tuta absoluta and the mirid predators Campyloneuropsis infumatus, Engytatus varians, Macrolophus basicornis, Macrolophus pygmaeus and Nesidiocorus tenuis.

\begin{tabular}{|c|c|c|c|c|c|c|c|c|c|}
\hline Species & Tomato CV & $R_{0}$ & $\mathrm{~T}$ & $r_{\mathrm{m}}$ & TD & $\lambda$ & Temp ${ }^{\circ} \mathrm{C}$ & Approach & Reference \\
\hline T. absoluta & Bravo & 68.30 & 26.30 & 0.16 & 4.30 & 1.17 & 25 & Birch + Jackknife & Silva et al. (2015) \\
\hline T. absoluta & St Clara & 39.62 & 40.25 & 0.09 & & 1.09 & 20 & Chi (2009) two-sex life table & Krechemer \& Foerster (2017) \\
\hline T. absoluta & St Clara & $\sim 24$ & & $\sim 0.10$ & & & 26 & Birch & Martins et al. (2016) \\
\hline C. infumatus & St Clara & 64.97 & 34.99 & 0.1192 & 4.31 & 1.13 & 24 & Birch + Jackknife & Silva et al., 2016 \\
\hline E. varians & St Clara & 59.53 & 37.89 & 0.1078 & 4.73 & 1.11 & 24 & Birch + Jackknife & Silva et al. (2016) \\
\hline M. basicornis & St Clara & 86.67 & 40.29 & 0.1107 & 4.59 & 1.12 & 24 & Birch + Jackknife & Silva et al. (2016) \\
\hline
\end{tabular}

$R_{0}=$ net reproductive rate; $T=$ mean generation time; $r_{\mathrm{m}}=$ intrinsic rate of increase; TD time required for the population to double in number and $\lambda=$ the finite rate of increase.

do not give any information about their predation capacity. Thus, we cannot conclude that $C$. infumatus $\left(r_{\mathrm{m}}=0.1192\right)$ is potentially a better predator than $E$. varians $\left(r_{\mathrm{m}}=0.1078\right)$ and $M$. basicornis $\left(r_{\mathrm{m}}=0.1107\right)$. This is why we mentioned in the introduction of this paper that $r_{\mathrm{m}}$ values for predators are not a suitable aggregate parameter for comparison of their biocontrol potential. Instead, we recommend using the pest kill rate for comparison of predators, also because this parameter can be used to compare the pest control capacity of parasitoids with that of predators. Further, this aggregate parameter appeared be a good predictor for selecting the best Orius species for thrips control (Tommasini et al., 2004).

Pest kill rates for the three Neotropical mirids were calculated with the approximating method earlier used by
Tommasini et al. (2004) and with the more accurate LotkaEuler equation (table 5). First of all, it is obvious that the kill rate values obtained with the Lotka-Euler equation are much higher than values obtained with the approximating method. This can be explained by the approximation of $T_{\mathrm{k}}$. In the calculation of $r_{\mathrm{m}}$ only adults are accounted for, while for the calculation of $k_{\mathrm{m}}$ both nymphs and adults are taken into account. Since the value of $k_{\mathrm{m}}$ is determined to a great extent by the rate of predation during the nymphal ages and not only during the adult stage, the use of the approximation of $T_{\mathrm{k}}$ which is a weighted average over all the ages where predation occurs can produce an underestimate of $k_{\mathrm{m}}$ (see Birch (1948) for details). In the past, without having powerful computers, it was very laborious to estimate $r_{\mathrm{m}}$ and $k_{\mathrm{m}}$ values with the 
Lotka-Euler equation, but nowadays it is easy and, therefore, we propose to use this more accurate equation in the future. Secondly, all pest kill rates obtained by the Lotka-Euler equation (0.2714-0.2969) are considerably higher than the $r_{\mathrm{m}}$ value for T. absoluta (0.1907), suggesting that all three Neotropical mirids, on the premise that they efficiently find prey, can kill more pest eggs per unit of time than the pest can produce. Thirdly, the kill rate of females of the three species is higher than that of males and that of both sexes, which is not surprising when looking at longevity and egg predation data (table 4, fig. 1). Fourthly, the ranking obtained by $r_{\mathrm{m}}$ values (C. infumatus best, next $M$. basicornis, last $E$. varians) is completely different from the ranking obtained by $k_{\mathrm{m}}$ values (E. varians best, $C$. infumatus second and $M$. basicornis last). The fact that $E$. varians ranks first when using $k_{\mathrm{m}}$ values is caused by its shorter generation time and higher daily predation (table 4). Thus, based on using only $k_{\mathrm{m}}$ values, we would conclude that $E$. varians might be the best candidate for control of T. absoluta on tomato in Brazil and this is contrary to what we concluded in our earlier papers on rates of population growth and functional responses (Silva et al., 2016; van Lenteren et al., 2016). In order to test whether E. varians is really the best predator for control of T. absoluta, greenhouse experiments need to be carried out under practical tomato production conditions, which we have not yet been able to perform.

In conclusion, for future selection of arthropod natural enemies, we propose to use the criteria listed in table 1 to quickly eliminate clearly unsuitable species. Next, for ranking of pest kill ability of arthropod natural enemies, we recommend to use the pest kill rate $k_{\mathrm{m}}$ and no longer the intrinsic rate of natural increase $r_{\mathrm{m}}$, because (1) $r_{\mathrm{m}}$ values have no predictive value for the pest kill capacity of predators, (2) $r_{\mathrm{m}}$ values have limited predictive value for the pest kill capacity of parasitoids, as parasitoids may kill a considerable number of hosts by nonreproductive effects, and (3) use of $k_{\mathrm{m}}$ makes it possible to compare the pest kill potential of parasitoids and predators. A disadvantage of determining the pest kill rate is the amount of time and plant, pest and natural enemy material needed. However, the advantages are not limited to the three points mentioned above, because determination of the pest kill rate also provides data about developmental times, mortalities of various developmental stages, sex ratios and peak predation periods. This information is essential for developing mass production methods and natural enemy release strategies.

\section{Supplementary material}

The supplementary material for this article can be found at https://doi.org/10.1017/S0007485319000130

\section{Acknowledgements}

Lisa Broekhuizen, Ana Maria Calixto, Jolein Smit and Marianne Soares are thanked for collection of the data on nymphal and adult predation. Professor Dr J.R.P. Parra (Department of Entomology and Acarology, (USP/ESALQ), Piracicaba, Brazil) is thanked for the provision of laboratory space. The Coordination for the Improvement of Higher Education Personnel (CAPES, Brazil) for travel grants to V. H.P. Bueno within the CAPES/Nuffic Programme Project 044/12, and for a research grant to F.C. Montes; the National Council for Scientific Research (CNPQ) for general financial support to this project; and the Laboratory of Entomology of Wageningen University for travel grants to L. Broekhuizen,
J. Smit and J.C. van Lenteren within the CAPES/NUFFIC Programme Project 044/12.

\section{References}

Abram, P.K., Brodeur, J., Urbaneja, A. \& Tena, A. (2019) Nonreproductive effects of insect parasitoids on their hosts. Annual Review of Entomology 64, 259-276. https://doi.org/10. 1146/annurev-ento-011118-111753.

Bale, J. (2011) Harmonization of regulations for invertebrate biocontrol agents in Europe, progress, problems and solutions. Journal of Applied Entomology 135, 503-513. https://doi.org/ 10.1111/j.1439-0418.2011.01611.x.

Biondi, A., Guedes, R. N. C., Wan, F. H. \& Desneux, N. (2018) Ecology, worldwide spread, and management of the invasive South American tomato pinworm, Tuta absoluta: past, present, and future. Annual Review of Entomology 63, 239-258. https://doi.org/10.1146/annurev-ento-031616-034933.

Birch, L.C. (1948) The intrinsic rate of natural increase of an insect population. Journal of Animal Ecology 17, 15-26.

Bueno, V.H.P., van Lenteren, J.C., Lins, J.C. Jr, Calixto, A.M. Montes, F.C., Silva, D.B., Santiago, L.D. \& Pérez, L.M. (2013) New records of Tuta absoluta (Meyrick) (Lepidoptera: Gelechiidae) predation by Brazilian Hemipteran predatory bugs. Journal of Applied Entomology 137, 29-34. https://doi. org/10.1111/jen.12017.

Bueno, V.H.P., Calixto, A.M., Montes, F.C. \& van Lenteren, J.C. (2018a) Population growth parameters of three Neotropical mirid predators (Hemiptera: Miridae) at five temperatures on tobacco with Ephestia kuehniella Zeller (Lepidoptera: Pyralidae) eggs as food. Israel Journal of Entomology 48(2), 122. http://doi.org/10.5281/zenodo.1185333.

Bueno, V.H.P., Montes, F.C., Sampaio, M.V., Calixto, A.M. \& van Lenteren, J.C. (2018b) Performance of immatures of three Neotropical Miridae at five temperatures when reared on Ephestia kuehniella eggs on tobacco plants. Bulletin of Insectology 71(1), 77-87.

Castañé, C., Arnó, J., Gabarra, R. \& Alomar, O. (2011) Plant damage to vegetable crops by zoophytophagous mirid predators. Biological Control 59, 22-29.

Chi, H. (2009) TWOSEX-MSChart: a computer program for the age-stage, two-sex life table analysis. http://140.120.197. 173/Ecology/. Last accessed 01-08-2018.

Cock, M.J.W., Murphy, S.T., Kairo, M.T.K., Thompson, E., Murphy, R.J. \& Francis, W.A. (2016) Trends in the classical biological control of insect pests by insects: an update of the BIOCAT database. Biological Control 61, 349-363.

DeBach, P. (1964) Biological Control of Insect Pests and Weeds. London, Chapman \& Hall.

Ferracini, C., Bueno, V.H.P., Dindo, M.L., Ingegno, B.L., Luna, M.G., Salas Gervassio, N.G., Sanchez, N.E., Siscaro, G, van Lenteren, J.C., Zappalà, L. \& Tavella, L. (2019) Natural enemies of Tuta absoluta in the Mediterranean basin, Europe and South America. Biocontrol Science and Technology. 29, in press. https://doi.org/10.1080/09583157.2019.1572711.

Heimpel, G.E. \& Mills, N.J. (2017) Biological Control: Ecology and Applications. Cambridge, Cambridge University Press, https://doi.org/10.1017/9781139029117.

Janssen, A. \& Sabelis, M.W. (1992) Phytoseiid life-histories, local predator-prey dynamics, and strategies for control of tetranychid mites. Experimental \& Applied Acarology 114, 233-250.

Krechemer, F.S. \& Foerster, L.A. (2017) Development, reproduction, survival, and demographic patterns of Tuta absoluta 
(Meyrick) (Lepidoptera: Gelechiidae) on different commercial tomato cultivars. Neotropical Entomology 46, 694-700, 10.1007/s13744-017-0511-5.

Lotka, A.J. (1907) Relation between birth rates and death rates. Science 26, 21-22.

Lotka, A.J. \& Sharpe, F.R. (1911) A problem in age distribution. Philosophical Magazine Series 6 21, 339-345.

Maia, A.H.N., Luiz, A.J. \& Campanhola, C. (2000) Statistical inference on associated fertility life table parameters using Jackknife technique: computational aspects. Journal of Economic Entomology 93(2), 511-518.

Martins, J.C., Picanco, M.C., Bacci, L., Guedes, R.N.C., Santana, P.A. Jr., Ferreira, D.O. \& Chediak, M. (2016) Life table determination of thermal requirements of the tomato borer Tuta absoluta. Journal of Pest Science 89, 897-908.

Mason, P.G., Cock, M.J.W., Barratt, B.I.P., Klapwijk, J., van Lenteren, J.C., Brodeur, J., Hoelmer, K.A. \& Heimpel, G.E. (2018) Best practices for the use and exchange of invertebrate biological control genetic resources relevant for food and agriculture. Biological Control 63, 149-154.

McEvoy, P.B. (2018) Theoretical contributions to biological control success. Biological Control 63, 87-103. https://doi.org/10. 1007/s10526-017-9852-6.

Mollá, O., Biondi, A., Alonso-Valiente, M. \& Urbaneja, A. (2014) A comparative life history study of two mirid bugs preying on Tuta absoluta and Ephestia kuehniella eggs on tomato crops: implications for biological control. Biological Control 59, 175$183,10.1007 /$ s10526-013-9553-8.

Pérez-Hedo, M. \& Urbaneja, A. (2016) The zoophytophagous predator Nesidiocoris tenuis: a successful but controversial biocontrol agent in tomato crops. pp. 121-138 in Horowitz, A. R. \& Ishaaya, I. (Eds) Advances in Insect Control and Resistance Management. Dordrecht, Springer.

Silva, D.B., Bueno, V.H.P., Lins, J.C. Jr \& van Lenteren, J.C. (2015) Life history data and population growth of Tuta absoluta at constant and alternating temperatures on two tomato lines. Bulletin of Insectology 68(2), 223-232.

Silva, D.B., Bueno, V.H.P., Montes, F.C. \& van Lenteren, J.C. (2016) Population growth of three mirid predatory bugs feeding on eggs and larvae of Tuta absoluta on tomato. Biological Control 60, 545-553, 10.1007/s10526-016-9736-1.

Silva, D.B., Bueno, V.H.P., Calvo, F.J. \& van Lenteren, J.C. (2017) Do nymphs and adults of three Neotropical zoophytophagous mirids damage leaves and fruits of tomato? Bulletin of Entomological Research 107, 200-207, 10.1017/S0007485316000778.

Silva, D.B., Bueno, V.H.P., Peñaflor, M.F.G.V., Bento, J.M.S. \& van Lenteren, J.C. (2018) Attraction of three mirid predators to tomato infested by both the tomato leaf mining moth Tuta absoluta and the whitefly Bemisia tabaci. Journal of Chemical Ecology 44, 29-39. https://doi.org/10.1007/s10886-017-0909-x.

Southwood, T.R.E. (1966) Ecological Methods with Particular Reference to the Study of Insect Populations. London, Methuen.

Stiling, P. \& Cornelissen, T. (2005) What makes a successful biocontrol agent? A meta-analysis of biological control agent performance. Biological Control 34, 236-246.

Tommasini, M.G., van Lenteren, J.C. \& Burgio, G. (2004) Biological traits and predation capacity of four Orius species on two prey species. Bulletin of Insectology 57, 79-94.

Urbaneja, A., González-Cabrera, J., Arnó, J. \& Gabarra, R. (2012) Prospects for the biological control of Tuta absoluta in tomatoes of the Mediterranean basin. Pest Management Science 68, 1215-1222. https://doi.org/10.1002/ps.3344.

van Driesche, R.D. \& Bellows, T.S. (1996) Biological Control. New York, Chapman \& Hall.

van Lenteren, J.C. (1980) Evaluation of control capabilities of natural enemies: does art have to become science? Netherlands Journal of Zoology 30, 369-381.

van Lenteren, J.C. (2010) Ecology: Cool Science, But Does it Help? Wageningen, Wageningen University.

van Lenteren, J.C. \& Woets, J. (1988) Biological and integrated pest control in greenhouses. Annual Review of Entomology 33, 239-269.

van Lenteren, J.C., Bale, J., Bigler, F, Hokkanen, H.M.T. \& Loomans, A.J.M. (2006) Assessing risks of releasing exotic biological control agents of arthropod pests. Annual Review of Entomology 51, 609-634. + supplemental material. doi: 10.1146/annurev.ento.51.110104.151129.

van Lenteren, J.C., Hemerik, L., Lins, J.C. Jr. \& Bueno, V.H.P. (2016) Type II and III functional responses of three Neotropical mirid predators when exposed to a range of densities (4-256) of eggs of Tuta absoluta on tomato. Insects 7(34) doi: 10.3390/ insects7030034.

van Lenteren, J.C., Bueno, V.H.P., Smit, J., Soares, M.A., Calixto, A.M., Montes, F.C. \& de Jong, P. (2017) Predation of Tuta absoluta eggs during the nymphal stages of three Neotropical mirid predators on tomato. Bulletin of Insectology 70, 69-74.

van Lenteren, J.C., Bueno, V.H.P., Montes, F.C., Hemerik, L. \& de Jong, P. (2018a) Adult lifetime predation of Tuta absoluta eggs by three Neotropical mirid predators on tomato. Bulletin of Insectology 71(2), 179-188.

van Lenteren, J.C., Bolckmans, K., Kohl, J., Ravensberg, W. \& Urbaneja, A. (2018b) Biological control using invertebrates and microorganisms: plenty of new opportunities. Biological Control 63, 39-59, 10.1007/s 10526-017-9801-4. 